\title{
Н.К
}

HOLISTIK JURNAL KESEHATAN

ISSN 1978-3337 (Print)

ISSN 2620-7478 (Online)

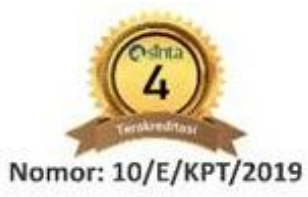

INFORMASI ARTIKEL

Received: April, 06, 2021

Revised: May, 22, 2021

Available online: May, 25, 2021

at : http://ejurnalmalahayati.ac.id/index.php/holistik

\section{Penggunaan hipnoterapi untuk menurunkan nyeri pada ibu post seksio sesarea}

\section{Asyima*, Ikrawanty Ayu Wulandari}

Akademi Kebidanan Pelamonia Kesdam VII/wirabuana.

Korespondensi Penulis: Asyima. Email: asyimarukman@gmail.com

\begin{abstract}
Hypnotherapy as a treatment for pain in patients with post-cesarean delivery pain
\end{abstract}

Background: The (22\%) of secsio cesaria occurred at age 35-49 years, (19\%) first delivery, (19\%), living in urban areas $(23 \%)$, highly educated and $(32 \%)$ in the top wealth quintile of $7 \%$ done in a planned manner (SC selective). Secsio cesaria (SC) causes pain and various problems. The hypnotherapy process can reduce pain because of modulation or strengthening of impulses from weak impulses / weak stimuli which are then strengthened so that they can immediately reach the brain and are immediately felt as well. Give a response so that post partum where the intensity of the pain experienced can adapt.

Purpose: To determine the effectiveness of hypnotherapy as a treatment for pain in patients with post-cesarean delivery pain

Method: A quasi-experimental by pretest and posttest approach, the sample divided into 2 groups, intervention and control, each of which was 15 samples. The pain evaluation by Numeric Rating Scale (NRS).

Results: There was a significant difference in both groups with $p$-value of $p=0.000$, this shows that there is a significant effectiveness of hypnotherapy as a treatment for pain in patients with post-cesarean delivery pain Conclusion: Finding that the effectiveness of hypnotherapy as a pain treatment in patients with post-cesarean labor pain at Tk.II Pelamonia Hospital.

Keywords: Hypnotherapy; Treatment; Patients; Post-cesarean; Delivery pain

Pendahuluan : Persentase bedah caesar paling banyak terjadi umur 35-49 tahun (22\%), kelahiran pertama $(19 \%)$, tinggal di perkotaan $(23 \%)$, berpendidikan tinggi dan berada pada kuintil kekayaan teratas (masingmasing 32\%), dan sebesar 7\% persalinan di laksanakan secara terencana (SC selektif). Tindakan secsio cesaria (SC) menyebabkan nyeri yang menimbulkan berbagai masalah. Proses hipnoterapi dapat mengurangi nyeri karena adanya modulasi atau penguatan impuls dari impuls yang lemah/rangsangan yang lemah kemudian diperkuat agar dapat segera sampai kedalam otak dan segera dipersepsikan untuk segara pula tersebut senantiasa dilakukan dengan memberikan respon agar ibu post partum dimana intensitas nyeri yang di alami dapat beradaptasi.

Tujuan : Untuk mengetahui efektifitas pemberian hypnoterapi terhadap penurunan respon nyeri ibu post seksio sesarea 
Metode :Penelitian Quasi Eksperimen pendekatan pretes dan post tes sampel dibagi menjadi 2 kelompok yaitu intervensi dan control masing-masing 15 sampel jadi total sampel sebanyak 30 partisipan. Evaluasi nyeri dengan menggunakan Numeric Rating Scale (NRS).

Hasil: Terdapat perbedaan yang bermakna pada kedua kelompok dengan $p$-value $p=0,000$ hal ini menunjukkan terdapat pengaruh yang signifikan hipnoterapi sebagai pengobatan penurunan respon nyeri ibu post secsio sesarea.

Simpulan: Didapatkan pengaruh pemberian hypnoterapi terhadap penurunan respon nyeri ibu post seksio sesarea di Rumah Sakit Tk.II Pelamonia.

\section{Kata Kunci: Hipnoterapi; Nyeri; Post seksio sesarea}

\section{PENDAHULUAN}

Kementerian kesehatan telah mewajibkan persalinan ditolong oleh tenaga kesehatan yang kompoten, hal ini merupakan upaya untuk mencapai target Sustainable Development Goals (SDG's) atau Tujuan Pembangunan Berkelanjutan (TBP) dalam menurunkan angka kematian ibu (AKI) secara global kurang dari 70 per 100.000 kelahiran hidup di tahun 2030. Laporan SDKI 2017 menunjukkan bahwa 17 persen kelahiran hidup dalam 5 tahun sebelum survei dari wanita 15-49 tahun yang di lahirkan melalui proses bedah Caesar (Astasia \& Faeni, 2020; Kementerian Kesehatan Republik Indonesia, 2017).

Persentase persalinan bedah Caesar paling banyak terjadi pada wanita yang bersalin saat umur 35-49 tahun (22\%), wanita dengan kelahiran pertama (19\%), wanita yang tinggal di perkotaan $(23 \%)$, wanita berpendidikan tinggi dan berada pada kuintil kekayaan teratas (masing-masing $32 \%$ ), sebesar $7 \%$ persalinan melalui beda Caesar di laksanakan secara terencana (SC selektif) (Saputera et al., 2020; Wulandari et al., 2018; Anggraeni et al., 2020).

Manfaat dari pemberian hypnoterapi pada ibu pos SC adalah memberikan sugesti berupa afirmasi atau kalimat perintah, Hal tersebut dimaksudkan agar objek hypnosis mampu segera masuk kealam pikiran bawah sadar sehingga membuat ibu merasa rileks (Fitriani, 2014; Steel et al., 2016).

Penelitian ini bertujuan untuk mengurangi nyeri post secsio sesarea pada ibu, sehingga kemampuan mobilisasi dini segera berlangsung dan ibu dapat memberikan ASI sedini mungkin kepada bayinya. Adapun risiko peningkatan pemberian susu formula pada ibu dengan post secsio, yang biasanya disebabkan karena

ketakutan beraktifitas pada ibu karena trauma nyeri pada daerah luka, sehingga terapi hypoterapi dapat mengurangi nyeri yang dirasakan (Heryani \& Denny, 2017; Catsaros \& Wendland, 2020).

Persalinan Caesar atau sectio Caesarean (SC) adalah prosedur pembedahan di mana janin dilahirkan melalui sayatan di perut ibu dan di Rahim ibu (Quinn, Kinsella, Gorton, Knight, Columb, Robson, \& Mushambi, 2017). Setiap pembedahan selalau berhubungan dengan insisi/sayatan yang merupakan trauma yang menimbulkan berbagai keluhan dan gejala salah satu keluhan yang sering dikemukakan adalah nyeri, nyeri akut adalah pengalaman sensori dan emosi yang tidak menyenangkan akibat adanya kerusakan jaringan yang actual atau potensial, atau digambarkan dengan istilah seperti (internasional association for study of pain) awitan yang tiba-tiba atau berlahan dengan intensitas ringan sampai berat dengan akhir yang dapat di antisipasi atau dapat diramalkan dan durasinya kurang dari enam bulan.(Navisah et al., 2017; Aini \& Pratidina, 2017; Catsaros \& Wendland, 2020).

Nyeri adalah pengalaman sensorik dan emosional yang tidak menyenangkan berhubungan dengan adanya kerusakan jaringan atau cenderung akan cenderung akan terjadi kerusakan jaringan (Aisyah, 2017; Wahyuningtyas \& Tugasworo, 2015). Fisiologi nyeri pada pasien pasca operasi adalah nyeri yang diawali sebagai respon yang diterima oleh saraf-saraf perifer. Zat kimia seperti subtansi $P$, bradikinin dan prostaglandin dilepaskan kemudian menstimulasi saraf perifer,membantu mengantarkan rangsang nyeri dari daerah yang terluka ke otak,sinyal nyeri dari daerah yang terluka berjalan sebagai impuls elektrokimia di sepanjang saraf ke bagian dorsal spina cord(daerah pada spinal yang menerima

Asyima*, lkrawanty Ayu Wulandari

Akademi Kebidanan Pelamonia Kesdam Vlı/wirabuana.

Korespondensi Penulis: Asyima. Email: asyimarukman@gmail.com

DOI: https://doi.org/10.33024/hjk.v15il.4176 
sinyal dari seluruh tubuh),pesan kemudian diantarkan ke thalamus, yaitu pusat sensori di otak dan sensasi di otak, selanjutnya diantarkan ke kortex dimana intensitas dan lokasi nyeri dipersepsikan (Mardana \& Aryasa, 2017; Widiatie, 2015; Oliver, 2017).

Hypnosis adalah kondisi sadar yang terjadi secara alami, dimana sesepartisipan mampu menghayati pikiran dan sugesti tertentu untuk mencapai perubahan psikologis, fisik maupun spiritual yang diinginkan (Hakim, 2010; Supriatiningsih, Rudiyanti, \& Rizqi, 2020).

Relaksasi hypnobirthing memberika sugesti positif pada diri ibu,sugesti ini mengubah gelombang otak beta (conscious mind) menjadi gelombang otak alpha (unconscious mid) di korteks selebri kemudian terjadi proses asosiasi penginderaan dimana rangsangan analisis (Aprillia, 2010; Ratna, 2017).

Relaksasi hypnobirthing akan menuntun agar tetap dalam kondisi rileks dan sama sekali tidak memikirkan dan merasakan nyeri yang ditimbulkna oleh bekas luka operasi dan involusio uterus (Kuswandi, 2011; Haniyah et al., 2016; Rahmawati et al., 2013).

\section{METODE}

Penelitian ini menggunakan desain quasi eksperiment dengan pendekatan pretes dan posttes pada dua kelompok yaitu intervensi dan kontrol. Evaluasi untuk melihat penurunan nyerinya menggunakan skala Numeric Rating Scale (NRS) pelaksanaannya di ruang nifas Rumkit TK.II Pelamonia dimana jumlah Pasien sebanyak 30 partisipan Post Sectio Saesarea yang dibagi menjadi 2 kelompok yang terdiri 15 partisipan kelompok intervensi (yang dilakukan Hypnotherapi) dan 15 partisipan kelompok control (yang tidak dilakukan hypnotherapy) untuk mengetahui apakah ada penurunan nyeri pada pasien yang telah dilakukan perlakukan. Sampel yang digunakan memenuhi criteria dengan tehnik purposive sampling dengan kriteria berumur 20-35 tahun, post secsio hari ke-2 dan ke-3, tidak mengalami komplikasi dan menggunakan terapi anastesi. Adapun tahapan pelaksanaannya hypnotherapi dilakukan pada saat dengan kondisi partisipan dalam keadaan rilek serta dengan memperhatikan ruangan/lingkungan sekitar harus dalam keadaan tenang, di lakukan secara perorangan/perindividu, alokasi waktu yang di gunakan sekitar 20-30 menit dengan 3 tahapan yaitu: tahap persiapan, tahap pelaksanaan dan tahap akhir /penutup.

Setelah semua proses dilakukan maka diakhiri dengan pengukuran nyeri dengan menggunakan skala pengukuran nyeri Numeric Rating Scale (NRS) yaitu salah satu alat diagnostik yang digunakan untuk mengetahui kualitas nyeri yang dialami partisipan. Partisipan diminta untuk memilih angka di antara 0-10. Angka 0 menandakan tidak nyeri dan 10 menandakan nyeri yang sangat hebat.

NRS dikembangkan dari VAS dan sangat efektif untuk pasien-pasien pembedahan dan sering digunakan secara rutin untuk mengkaji pasien yang mengalami nyeri di unit operasi (Rhonda, \& Rospond, 2013; Black \& Hawks, 2013; Brunelli, \& Brunelli 2012).

Data di olah dengan menggunakan SPSS versi 21 secara univariat dan bivariat. Analisis univariat dilakukan untuk menilai distribusi dari setiap variable pada penelitian. Sementara Analisis bivariat menggunakan Uji $t$ independent untuk menilai perbedaan antara kelompok intervensi dan control.

Penelitian ini telah mendapatkan uji layak etik dari komisi etik penelitian RSPTN Universitas Hasanuddin Makassar No.326/UNH4.6 $4 / 5.2 .0 / 2020$
Asyima*, lkrawanty Ayu Wulandari

Akademi Kebidanan Pelamonia Kesdam VII/wirabuana.

Korespondensi Penulis: Asyima. Email: asyimarukman@gmail.com 
HASIL

Tabel 1. Data Demografi Responden

\begin{tabular}{lcc}
\hline Variabel & Intervensi $(\mathbf{n}=\mathbf{1 5})$ & Kontrol $(\mathbf{n}=15)$ \\
\hline Umur & & \\
<25 Tahun & $1 / 3.4$ & $2 / 6.7$ \\
25-35 Tahun & $11 / 36.6$ & $10 / 33.3$ \\
>35 Tahun & $3 / 10.0$ & $3 / 10.0$ \\
& & \\
Pendidikan (n/\%) & $11 / 36,7$ & $10 / 33.3$ \\
Tinggi & $4 / 13,3$ & $5 / 16.7$ \\
Rendah & & \\
Pekerjaan (n/\%) & $11 / 36.7$ & $12 / 40.0$ \\
Bekerja & $4 / 13.3$ & $3 / 10.0$ \\
Tidak Bekerja & & \\
& & \\
Paritas (n/\%) & $5 / 16.7$ & $6 / 20,0$ \\
Primipara & $10 / 33.3$ & $8 / 26.7$ \\
Multipara & $0 / 0$ & $1 / 3.3$ \\
Grandemultipara & & \\
Riwayat SC (n/\%) & & $10 / 33.3$ \\
Pertama Kali & & \\
Berulang & $6 / 20.0$ & $5 / 16.7$ \\
\end{tabular}

Berdasarkan tabel 1 diperoleh hasil bahwa dari 30 partispan berdasarkan umur pada kelompok intervensi maupun kelompok kontrol didominasi pada umur 25-35 tahun. Pada kedua kelompok mayoritas berlatar belakang pendidikan tinggi, status bekerja/wanita karir, dengan paritas multi. Sedangkan riwayat SC pada kelompok intervensi didominasi mempunyai riwayat berulang sedangkan pada kelompok kontrol didominasi pada pertama kali SC.

Tabel 2. Analisis Hypnoterapi Terhadap Intensitas Nyeri

\begin{tabular}{lllccc}
\hline Variabel & Kelompok & $\mathrm{n}$ & Mean & Std.Deviation & $\mathrm{p}$-value \\
& & & & & \\
\hline Intensitas & Perlakuan & 15 & 2.4667 & 0.51640 & 0,000 \\
Nyeri & Kontrol & 15 & 3.6667 & 1.23443 & \\
\hline
\end{tabular}

Berdasarkan Tabel diatas, dimana nilai $p=0.000<$ dari nilai $a=0,005$, maka dapat disimpulkan bahwa ada pengaruh pemberian hypnotherapy pada pasien yang kelompok perlakuan dan kelompok kontrol terhadap penurunan nyeri, ini juga menunjukkan bahwa ada pengaruh secara bermakna hypnotherapy terhadap penurunan intensitas nyeri. Hasilnya pengaruh pemberian hypnotherapy pada pasien yang kelompok perlakuan dan kelompok kontrol terhadap penurunan nyeri menunjukkan bahwa ada pengaruh secara bermakna hypnotherapy terhadap penurunan intensitas nyeri pada pasien post section caesarea.

Asyima*, lkrawanty Ayu Wulandari

Akademi Kebidanan Pelamonia Kesdam Vll/wirabuana.

Korespondensi Penulis: Asyima. Email: asyimarukman@gmail.com

DOI: https://doi.org/10.33024/hjk.v15il.4176 


\section{PEMBAHASAN}

Proses hypnotherapy dapat mengurangi nyeri karena adanya modulasi atau penguatan impuls dari impuls yang lemah kemudian diperkuat agar dapat segera sampai kedalam otak dan segera dipersepsikan untuk segera pula memberikan rangsangan atau respon dalam hypnotherapy, hal ini senantiasa dilakukan dengan memberika sugesti atau afirmasi yang berupa kalimat perintah agar objek hypnosis masuk kedalam bawah alam sadar untuk mengerjakan sesuatu (Idris, 2019; Setyadi et al., 2015).

Penelitian ini sejalan dengan penelitian sebelumnya dimana perbedaan nyeri pada Pasien control terjadi akibat adanya luka insisi yang mengeluarkan mediator kimia nyeri seperti histamine, diman aobat analgetik maupun anastesi sudah mulai menurun maka pasien akan mengalami nyeri (Aini, \& Pratidina, 2017).

Pada Pasien yang mengalami intensitas nyeri tetap dapat dipengaruhi oleh beberapa faktor diantaranya adanya pengalaman masa lalu bila pasien perna mengalami nyeri dan berhasil mengatasinya maka partisipan tersebut dapat mentoleransi nyeri yang dirasakan saat ini.selain didalam tubuh tiap individu kadar endorphin dan enkefalin juga berbeda pada pasien yang mempunyai kadar yang sedikit akan mengalami nyeri, sedangkan pada pasien yang mempunyai kadar yang banyak akan lebih bisa mentoleransi nyeri.yang melakukan hypnobirthing di banding yang berpendidikan tinggi, sedangkan tingkat paritas ibu yang multi lebih banyak melakukan hypnobirthing di banding dengaa ibu yang primi dan gandemultipara,sedang untuk kelompok ibu yang riwayat SC dimana ibu yang pertama kali SC lebih banyak yang mengikuti Hypnobirthing di banding ibu yang riwayat SC yang berulang (Ngatwadi, Mudatsir, \& Mulyadi, 2018)

\section{SIMPULAN}

Hasil penelitian ini menunjukkan bahwa pemberian hypnotherapy pada pasien post section saesarea dapat mengurangi penurunan intensitas nyeri.

\section{SARAN}

Bagi manajemen rumah sakit Tingkat II

Pelamonia untuk memberikan pelatihan pada perawat atau bidan untuk menambah pengetahuan hynotherapi dan hypnobirthing untuk dapat menerapakan sebagai terapi alternatif membantu memenuhi kebutuhan pasien khususnya pada pasien yang mengalami intensitas nyeri yang tinngi.

\section{DAFTAR PUSTAKA}

Aini, F., \& Pratidina, E. S. G. (2017). Pengaruh Hipnoterapi terhadap Intensitas Nyeri Pada Pasien Post Section Cesarea di Rumah Sakit PKU Muhammadiyah Kabupaten Temanggung. Prosiding Seminar Nasional Dan Internasional, 1(1), 163-171.

Aisyah, S. (2017). Manajemen Nyeri Pada Lansia Dengan Pendekatan Non Farmakologi. Jurnal Keperawatan Muhammadiyah, 2(1). https://doi.org/10.30651/jkm.v2i1.1201

Anggraeni, W., Herliani, H. Y., \& Rohmatin, E. (2020). Gambaran Penyembuhan Luka Post Operasi Sectio Caesarea Dengan Pemberian Antibiotik Ceftizoxime Sebagai Profilaksis Dosis Tunggal Di Rumah Sakit Singaparna Medika Citrautama Kabupaten Tasikmalayatahun 2018. Jurnal Kesehatan Bidkesmas Respati, 2(10), 19. https://doi.org/10.48186/bidkes.v2i10.195

Aprilia, Y. (2010). Hipnostetri. Rileks Nyaman dan Aman saat Hamil dan Melahirkan. Jakarta. Gagas Media.

Astasia, A., \& Faeni, Y. A. (2020). Maternal Mortality Risk di Indonesia. Jurnal Sistem Cerdas, 03(02), 144-152.

Black, J. M., \& Hawks, J. H. (2013). Keperawatan Medikal Bedah Manajemen Klinis Untuk Hasil Yang Diharapkan (Vol. 10).

Asyima*, lkrawanty Ayu Wulandari

Akademi Kebidanan Pelamonia Kesdam Vll/wirabuana.

Korespondensi Penulis: Asyima. Email: asyimarukman@gmail.com

DOI: https://doi.org/10.33024/hjk.v15il.4176 
Brunelli, G. A., \& Brunelli, G. R. (2012). Preoperative assessment of the adult plexus patient. Microsurgery, 16(1), 17-21.

Catsaros, S., \& Wendland, J. (2020). Hypnosisbased interventions during pregnancy and childbirth and their impact on women's childbirth experience: A systematic review. In Midwifery (Vol. 84). Churchill Livingstone. https://doi.org/10.1016/j.midw.2020.102666

Fitriani, R. (2014). Pengaruh teknik relaksasi nafas dalam terhadap respon adaptasi nyeri pada pasien Inpartu Kala I Fase Laten Di RSKDIA Siti Fatimah Makassar Tahun 2013. Jurnal Kesehatan.

Hakim, A. (2010). Hypnosis in Teaching, Cara Dahsyat Mendidik dan Mengajar. Jakarta: Visiamedia

Haniyah, S., Setyawati, M. B., \& Sholikah, S. M. (2016). Efektifitas teknik relaksasi genggam jari terhadap nyeri post sectio caesarea di RSUD Ajibarang. Journal STIKes.

Heryani, R., \& Denny, A. (2017). Pengaruh mobilisasi dini terhadap penyembuhan luka post sectio caesarea. Jurnal Ipteks Terapan. https://doi.org/10.22216/iit.2017.v11i1.661

Idris, F. P. (2019). Pada Ibu Bersalin Normal di RSUD Labuang Baji Makassar. Jurnal IImiah Kesehatan Diagnosis, 14, 67-73.

Kementerian Kesehatan $\quad$ Republik
Indonesia.(2017). Izin dan penyelenggaraan
praktik bidan. Diakses dari
https://persi.or.id/wp-
content/uploads/2020/11/pmk282017.pdf

Kuswandi L. (2011). Keajaiban hypnobirthing. Jakarta : Pustaka Bunda; 2011.

Asyima*, Ikrawanty Ayu Wulandari

Akademi Kebidanan Pelamonia Kesdam VII/wirabuana.

Korespondensi Penulis: Asyima. Email: asyimarukman@gmail.com

DOI: https://doi.org/10.33024/hjk.v15il.4176
Mardana, I. K. R. P., \& Aryasa, T. (2017). Penilaian nyeri. Academia.

Navisah, F., Machmudah, \& Astuti, R. (2017). Perbedaan efektivitas mobilisasi dini dan bladder training terhadap waktu eliminasi bak pertama pada ibu post sectio caesarea di RSUD DR. H. Soewondo Kendal Fitrotun. Jurnal IImu Keperawatan Dan Kebidanan, 3(2), 77-85.

Ngatwadi, N., Mudatsir, M., \& Mulyadi, M. (2018). Perbedaan efektifitas pengaruh hypnotherapy dan teknik relaksasi nafas dalam terhadap nyeri sendi pada penderita arthritis rheumatoid. Jurnal IImu Keperawatan, 6(1), 15-30.

Oliver, J. (2017). Etiologi Nyeri Akut. Journal of Chemical Information and Modeling, 53(9), 1689-1699.

Quinn, A. C., Kinsella, S. M., Gorton, H. J., Knight, M., Columb, M. O., Robson, S. C., \& Mushambi, M. C. (2017). Neonatal outcomes after failed tracheal intubation during obstetric general anaesthesia for caesarean section: Secondary analysis of a UKOSS case-control study. European Journal of Obstetrics and Gynecology and Reproductive Biology, 217.

Rahmawati, W. R., Arifah, S., \& Widiastuti, A. (2013). Pengaruh Pijat Punggung terhadap Adaptasi Nyeri Persalinan Fase Aktif Lama Kala II dan Perdarahan Persalinan pada Primigravida. Kesmas: National Public Health Journal.

https://doi.org/10.21109/kesmas.v8i5.385

Ratna, W. P. (2017). Casual Hypnosis For Affecting People. Anak Hebat Indonesia. 
Rhonda, J. M., \& Rospond, M. R. (2013). Patient assessment in pharmacy practice. Battimore: Lippincott Williams \& wilkins.

Saputera, M. M. A., Ahmad, A., Khumaira Sari, A., \& Soraya, A. (2020). Selisih tarif rumah sakit terhadap tarif ina-cbg's pada pasien sectio caesarea di rumah sakit daerah Idaman Banjarbaru Tahun 2019. Jurnal Insan Farmasi Indonesia, 3(2), 317-326. https://doi.org/10.36387/jifi.v3i2.599

Setyadi, A. W., Murti, B., \& Demartoto, A. (2015). The Effect of Hypnotherapy on Depression , Anxiety, and Stress, in People Living with HIV I AIDS, in Kediri , East Java. 99-108.

Steel, A., Frawley, J., Sibbritt, D., Broom, A., \& Adams, J. (2016). The characteristics of women who use hypnotherapy for intrapartum pain management: Preliminary insights from a nationally-representative sample of Australian women. Complementary Therapies in Medicine, 25 , $67-70$. https://doi.org/10.1016/i.ctim.2016.01.006

\footnotetext{
Asyima*, lkrawanty Ayu Wulandari
}

Akademi Kebidanan Pelamonia Kesdam VII/wirabuana.

Korespondensi Penulis: Asyima. Email: asyimarukman@gmail.com

DOI: https://doi.org/10.33024/hjk.v15il.4176
Supriatiningsih, H., Rudiyanti, N., \& Rizqi, I. (2020). Sosialisasi teknik hypnobirthing pada tenaga kesehatan, kader kesehatan dan ibu hamil di wilayah kerja Puskesmas Tanjung Bintang Lampung Selatan Tahun 2019. Sakai Sambayan Jurnal Pengabdian kepada Masyarakat, 4(3), 238-243.

Wahyuningtyas P., S. J., \& Tugasworo, D. (2015). Pengaruh derajat depresi dengan intensitas nyeri kronik: Studi pada pasien rawat jalan RSUP Dr. Kariadi Semarang. Jurnal Kedokteran Diponegoro, 4(4), 1460-1466.

Widiatie, W. (2015). Pengaruh Teknik Relaksasi Nafas Dalam Terhadap Penurunan Intensitas Nyeri Pada Ibu Postseksio Sesarea Di Rumah Sakit Unipdu Medika Jombang. Jurnal EduHealth, 5(2), 245442.

Wulandari, P., Maharani, R. P., \& Arifianto, A. (2018). Faktor-Faktor Yang Berhubungan Tindakan Persalinan Sectio Caesarea Di Rumah Sakit Santa Elisabeth Semarang. Journal of Holistic Nursing Science, 5(2), 6471. https://doi.org/10.31603/nursing.v5i2.2432 